\title{
EvoDevo Shapes the Extended Synthesis
}

\author{
Gerd B. Müller
}

Published online: 22 May 2014

(c) Konrad Lorenz Institute for Evolution and Cognition Research 2014

When the interfield of EvoDevo arose in the early 1980s, its momentum was fueled by both the methodological advances in molecular biology and the explanatory deficits of the standard evolutionary paradigm, the Modern Synthesis. Whereas the methodological progress led to a proliferation of empirical research, the implications of EvoDevo for evolutionary theory often went unnoticed or were actively sidelined by the stakeholders of the received theory. Only with the progressive corrosion of the Synthesis framework due to challenging evidence from several more fields (genomics, epigenetics, physiology, behavior, etc.) the tide started to change, and EvoDevo has become one of the key players in the current redefinition of evolutionary theory.

The evidence produced by EvoDevo mostly bears on the complexity of the genotype-phenotype rapport and the gene regulatory changes underlying its evolutionary transformation. It also elucidates the cell and tissue properties involved in the generation of complex structures, the physics and physiology governing these processes, as well as the quantitative assessment and modeling of generative procedures in evolutionary contexts. These results have tremendously improved our understanding of how development originated in the context of multicellularity, how its repertoires evolved, and how organismal change is mechanistically realized.

Gerd Müller is president of the European Society for Evolutionary Developmental Biology.

G. B. Müller $(\square)$

Department of Theoretical Biology, University of Vienna,

Vienna, Austria

e-mail: gerhard.mueller@univie.ac.at

G. B. Müller

KLI Institute, Klosterneuburg, Austria
EvoDevo has been equally prolific in the conceptual domain, contributing a wealth of new principles to the evolutionary model. Besides elaborations of such classical issues as heterochrony and developmental constraint, EvoDevo gave rise to new concepts such as facilitated variation, developmental modularity, morphoregulation, epigenetic innovation, developmental systems drift-to name but a few.

These provided improved understanding of the evolvability of developmental systems and their contribution to evolutionary robustness and non-gradual phenomena of phenotypic change. The result of these endeavors was a broadened interpretation of the role of development in the evolution of organismal complexity. Today it can be concluded with much confidence that the generation of selectable variation and phenotypic structure is not merely a consequence of genetic variation but also of the capacity of plastic developmental systems to respond to natural selection and direct environmental induction with integrated and often emergent reactions. Development not only constrains and facilitates the generation of phenotypic variation, but also affects the tempo, mode, and directionality of evolutionary change.

In concert with the evidence emerging from other fields of evolutionary biology, as briefly mentioned above, the findings of EvoDevo mean that nearly all assumptions central to the traditional Modern Synthesis framework have been overturned: evolution is not just a variational, continuous, and incremental kind of change but involves alternating speeds and discontinuous events; not all organismal features are independently adaptive, but certain traits are emergent and evolutionarily neutral; phenotypic variation is not merely a product of genetic variation that arises randomly and at constant rates but is equally a product of integrated development and plasticity; no single 
inheritance system carries information from one generation to the next, but, instead, multiple systems of inheritance are at play; no simple and direct connection governs the relation between genes and characters, but rather that relation is mediated by processes that involve recursive and nonlinear dynamics; natural selection does not provide the only "directional" factor in evolution-developmental constraints and generative propensities do as well.

Efforts towards the inclusion of these principles have resulted in a number of proposals for modification of the standard theory. They go by different names, but have often been described as "expanded" or "extended" synthesis (Kutschera and Niklas 2004; Müller 2007; Pigliucci 2007; Koonin 2009; Pigliucci and Müller 2010; Danchin et al. 2011; Wilson 2011; Schrey et al. 2012). A growing number of books equally reflects the increased sense of necessity for a major reform of evolutionary theory (Müller and Newman 2003; Odling-Smee et al. 2003; Bernardi 2005; Noble 2008; Bateson and Gluckman 2011; Gissis and Jablonka 2011; Koonin 2011; Shapiro 2011; Wagner 2011). The articles collected in this issue bear witness to these rich conceptual developments in evolutionary biology. They also demonstrate the influence of EvoDevo on the conceptualization of other fields. At the same time, several problems arising from such attempts at theory integration become apparent.

In their proposal of an EvoDevo agenda for comparative linguistics, Antonio Benítez-Burraco and Cedric Boeckx take up the issue of canalized variation and robustness. They argue that variation in the biological underpinnings of linguistic capacities is rooted in multiple levels of organization, development being a central one. The consequences of taking this source of diversity seriously into account challenge traditional Chomskyan concepts of Universal Grammar. The resulting agenda of "comparative biolinguistics" is an explicit departure from the "genetic variation alone drives evolution" dogma. In a complementary way, Rachael Brown looks at the EvoDevo of behavior and the origin of behavioral novelty. She argues that a meaningful application of the EvoDevo conceptual toolkit to the study of behavior requires operational criteria for the identification of novelty and a distinction of behavioral homology from non-homology.

Problems for explanatory pluralism that derive from "program" views of development, from the assumed universality of adaptation, and from restricted notions of causality are critically addressed in another three articles. Martin Flament-Fultot reviews various forms of representationalism in biology and argues that genes can be said to represent something only in a very restricted sense. He regards the program notion of DNA as an overstatement and proposes a new way to define what programs are. The related discussion of genes versus organisms and the role of adaptation are addressed by Philippe Huneman who identifies these two strands of controversy as running through all of evolutionary biology. In differentiating the natural selection view as a dynamics of alleles from the optimization view of economics, Huneman presents a thought-provoking analysis of these two interpretations, eventually asking whether the Modern Synthesis can indeed provide a theory of organisms. Besides addressing these issues in terms of neurobiology and cognition, he also devises an empirical test for the notion of genetic regulation and developmental programs. The more general problem of causation is taken up by Maximiliano Martínez and Maurizio Esposito. They argue that an Extended Synthesis account of evolution needs to depart from the traditional bottom-up models of causation and the associated "proximate/ultimate" dichotomy. They introduce the notion of "multilevel causation" with explicit reference, among others, to EvoDevo, phenotypic plasticity, and niche construction.

The problem of the origin of biological form, sidelined by the focus on variation in population-based accounts of evolution, is also addressed by several contributions. Diego Rasskin-Gutman and Borja Esteve-Altava call "Morphological EvoDevo" the field of inquiry in which explicit relations between evolutionary patterns and morphogenetic processes are made. They introduce a methodology for the study of anatomical connectivity networks that permits a formal and mathematical approach to the issue of constructional and developmental constraint in organismal evolution. How organismal form is generated is also Sheena Tyler's subject. She provides a historical analysis of the concept of morphogenetic field. The idea that development is governed by coordinating fields of force is an ancient one, but in her tracing of the empirical evidence for different kinds of field phenomena, Tyler revives the notion of coordinating fields in the context of modern molecular biology and the physical interpretation of morphogenesis, and she points to its practical uses in medical therapy. Laura Nuño de la Rosa offers a thoughtful analysis of EvoDevo's conceptual challenges to the standard theory of evolution in her essay review of the recent book by Caponi (2012). Concentrating on the concept of "morphospace," several central evolutionary phenomena such as the stability of form, the discrete nature of phenotypic variation, and the notion of internal selection are critically discussed.

Three book reviews also deal with conceptual issues of the ongoing debate about theory advancement in evolutionary biology. Internal versus external selection and the question of overarching adaptivity are discussed in Francesca Merlin's review of Randomness in Evolution; an argument for the inclusion of niche construction and EcoEvoDevo appears in Marion Blute's review of a recent 
biography of W. D. Hamilton, Nature's Oracle; the pros and cons of multiple levels of selection and inclusive fitness are addressed by Vidyanand Nanjundiah in his review of The Social Conquest of the Earth.

The vivid debate, by biologists and philosophers of science alike, of the theoretical consequences of EvoDevo and of novel concepts arising from other areas of biological research demonstrates the increasing awareness of theory expansion in evolutionary biology. Clearly, a redefinition of evolutionary theory is underway, regardless of whether traditionalists believe "to say the Modern Synthesis is incomplete or fatally flawed is fatuous" (Coyne in Whitfield 2008). While it is not yet possible to specify what an extended theory that encompasses substantially more factors than the classical version will look like precisely, it is safe to say that it will not concentrate on a single level of causation but, instead, will be pluralistic and multi-causal. It will include an account of the evolution of novelty and complexity, and the dominance of the variation-in-populations approach will recede. Such change entails significant shifts in theory structure, accounting-among other factors-for the dynamics of development, multiple levels of selection, different forms of inheritance, and reciprocity between environment and organismal activity (niche construction). The received theory, the Modern Synthesis framework, will become a special case: the explanation of variation in populations.

The appearance of this issue of Biological Theory coincides with the 5th meeting of the European Society for Evolutionary Developmental Biology in Vienna in July 2014. The continuous growth of the society and of the attendance of its biennial meetings are a testimony to the increasing importance of EvoDevo for both developmental and evolutionary biology. Recently a sister society has been founded, the Pan-American Society for Evolutionary Developmental Biology, with Ehab Abouheif as its first president. We welcome this new endeavor and look forward to fruitful interactions between the two societies. Together they are going to step up the formidable successes of EvoDevo and the reshaping of evolutionary theory.

\section{References}

Bateson P, Gluckman P (2011) Plasticity, robustness, development and evolution. Cambridge University Press, Cambridge

Bernardi G (2005) Structural and evolutionary genomics: natural selection in genome evolution. Elsevier, Amsterdam

Caponi G (2012) Réquiem por el Centauro: aproximación epistemológica a la biología evolucionaria del desarrollo. Centro de Estudios Filosóficos y Sociales Vicente Lombardo Toledano, México DC

Danchin E, Charmantier A, Champagne FA et al (2011) Beyond DNA: integrating inclusive inheritance into an extended theory of evolution. Nat Rev Genet 12(7):475-486

Gissis SB, Jablonka E (eds) (2011) Transformations of Lamarckism: from subtle fluids to molecular biology. MIT Press, Cambridge, MA

Jablonka E, Lamb MJ (2006) Evolution in four dimensions. MIT Press, Cambridge, MA

Koonin EV (2009) The Origin at 150: is a new evolutionary synthesis in sight? Trends Genet 25(11):473-475

Koonin EV (2011) The logic of chance: the nature and origin of biological evolution. FT Press, Upper Saddle River, NJ

Kutschera U, Niklas K (2004) The modern theory of biological evolution: an expanded synthesis. Naturwissenschaften 91(6):255-276

Müller GB (2007) Evo-devo: extending the evolutionary synthesis. Nat Rev Genet 8(12):943-949

Müller GB, Newman SA (eds) (2003) Origination of organismal form: beyond the gene in developmental and evolutionary biology. MIT Press, Cambridge, MA

Noble D (2008) The music of life. Oxford University Press, Oxford

Odling-Smee FJ, Laland KN, Feldman MW (2003) Niche construction: the neglected process in evolution. Princeton University Press, Princeton

Pigliucci M (2007) Do we need an extended evolutionary synthesis? Evolution 61(12):2743-2749

Pigliucci M, Müller GB (2010) Evolution: the extended synthesis. MIT Press, Cambridge, MA

Schrey AW, Richards CL, Meller V et al (2012) The role of epigenetics in evolution: the extended Synthesis. Genet Res Int. doi: $10.1155 / 2012 / 286164$

Shapiro JA (2011) Evolution: a view from the 21st century. FT Press, Upper Saddle River, NJ

Wagner A (2011) The origins of evolutionary innovations. Oxford University Press, Oxford

Whitfield J (2008) Biological theory: postmodern evolution? Nature 455(7211):281-284

Wilson LA (2011) The contribution of developmental palaeontology to extensions of evolutionary theory. Acta Zool. 1-7. Wiley Online Library 